\title{
The Relation of Corruption Perceptions, Conformity and Traditionalism: Macroeconomic Study of 52 Countries
}

\author{
Kamila Mestická \\ Faculty of Humanities, Charles University in Prague, U Kř̌že 8, 158 00, Prague 5, Prague, Czech Republic \\ Email: kamila.mesticka@gmail.com \\ Inna Čábelková \\ Faculty of Humanities, Charles University in Prague, U Kř̌že 8, 158 00, Prague 5, Prague, Czech Republic \\ Email: inna.cabelkova@fhs.cuni.cz
}

\section{Doi:10.5901/mjss.2015.v6n5p15}

\section{Abstract}

This paper analyses the relation of the subjective importance of values such as creativity, being rich, taking care of ourselves, helping others, being successful, excitement and adventure, behaving according to rules, taking care of the environment, tradition, living in secure surrounding in countries and the perceived levels of corruption in countries. In addition we study the effects of GDP per capita, and GDP per capita growth on corruption perceptions. We control for the level of education and urbanization. Our results suggest, that the more it is important to always behave properly; to avoid doing anything people would say is wrong, the higher is perceived corruption in the countries. The more it is important to comply with tradition and to follow the customs handed down by one's religion or family, the higher is the perceived corruption in the countries. The higher is natural logarithm of GDP per capita, the lower is perceived corruption. The higher is GDP growth, the higher is perceived corruption.

Keywords: corruption perceptions, conformiry, traditionalism.

\section{Introduction}

Economic literature discusses many factors that facilitate corruption. Scholars such as Mauro (1996), Tanzi (1998), RoseAckerman (1997), Hofstede (1991), Andvig (1991), cite as causes of corruption the lack of adequate legislation, poor law enforcement, cultural prerequisites, the lack of incentives government has to fight corruption, low wages for state officials. Cross-cultural literature on corruption explains the definitions and incidence of corruption with cultural differences or dimensions (see Lipset, and Lenz, 2000; Harrison and Huntington Eds., 2000; Sandholtz and Taagepera, 2005; DeBacker et al., 2012; Sims et al., 2012; Čábelková and Strielkowski, 2013; or Koudelkova et al., 2015). The reasons why corruption shall be understood as a cultural phenomenon are various. Corruption and corruption perception depends on how society understands the rules and what constitutes the deviation from it. Thus, it does not only depend on societies as itself but on the personal values and moral views prevailing in the society. For example someone might find bribes as very harmful and never do such a thing and someone else might find paying of a bribe in certain cases justifiable. In this paper we will study the association of subjective importance of values such as creativity, being rich, taking care of ourselves, helping others, being successful, excitement and adventure, behaving according to rules, taking care of the environment, tradition, living in secure surrounding in countries and the perceived levels of corruption in countries.

Besides studying the effect of values we readdress the relation between the levels of corruption perceptions and economic variables such as GDP per capita and GDP growth. While the relationship of CPI and GDP is well researched in the literature (see Japos, and Estrada, 2014; Okada and Samreth, 2012; Elbahnasawy, 2014; Iwasaki and Suzuki, 2012; or Sanderson and Strielkowski, 2013; or Strielkowski and Čábelková, 2014) and the results are consistent (all the researchers report positive statistically significant association), the results on CPI and GDP growth exhibit certain controversy. Though some authors report positive relation between GDP growth and corruption (see Braun and Di Tella, 2004; Frechette, 2006; Berdiev et al., 2013), the results if this study support negative statistically significant association of $\mathrm{CPI}$ and GDP growth. The graphical visualization of the relations between Corruption Perception Index (CPI) and GDP and GDP growth is presented on graphs 1 and 2. 


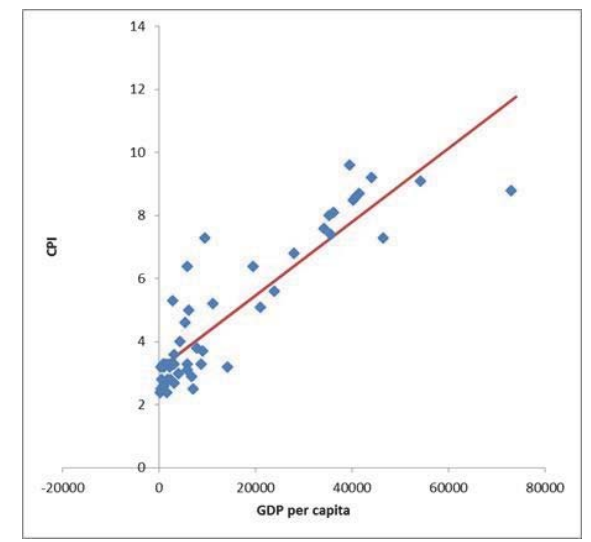

Graph 1. The relation between Corruption Perception Index (CPI) and GDP per capita, 2006

Source of the Data: Transparency International, World Bank. Own computations.

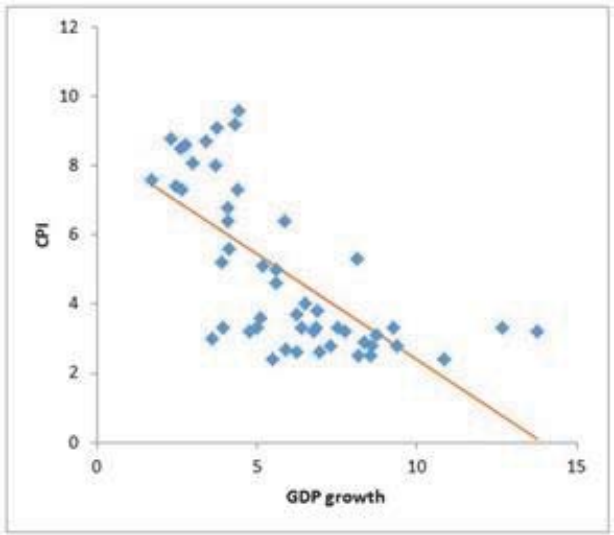

Graph 2. The relation between Corruption Perception Index and GDP growth, 2006

Source of the Data: Transparency International, World Bank. Own computations.

The lower is CPI the more corrupt is the country.

To study the relationships presented above we employ OLS regression analysis according to the specification presented in section Methodology. We control for the levels of education and urbanization. Our results suggest that the more it is important to always behave properly; to avoid doing anything people would say is wrong, the higher is perceived corruption in the countries. The more it is important to comply with tradition and to follow the customs handed down by one's religion or family, the higher is the perceived corruption in the countries. The higher is natural logarithm of GDP per capita, the lower is perceived corruption. The higher is GDP growth, the higher is perceived corruption.

\section{Literature Survey}

The research regarding personal values of the populations may be conducted in different ways. The first one is the analysis based on the personal characteristics like the gender, marital status, educational background, the place of residence and many others (Melgar, Rossi, Smith; 2010 or Mocan, 2008). Another approach understands to personal characteristics as the features of individuals' personality and temper connected with culture and analyse their effect on 
the national level (Husted, 1999; Connelly and Ones, 2008).

Melgar, et al (2010) analysed the foundations of corruption perception in a cross country perspective by using the dataset the module on Citizenship of 2004 of the International Social Survey Program. They found, that the personal characteristics play a significant role in shaping corruption perception. When focusing on country specific impacts the research had shown that a better economic performance reduces corruption perception. They found a significant gender difference, where women are more likely to perceive a higher level of corruption than men. According to the authors "the traditional gender roles have been changing in recent decades, although some influences remain. (Melgar, et al, 2010, s. 123). Furthermore, they found that age plays no significant role in perceiving of corruption. It is often argued that recent generations are socialized in different ways, but it does not affect the corruption.

Married people also tend to perceive lower level of corruption than those who are divorced which they explain with the fact, that divorce has a negative impact on shaping judgments about life. When debating the importance of the level of education it has shown that is has a strongly relevant role. People who have completed at least the secondary education tend to perceive lower level of corruption. This may be connected with the fact that more educated people have better access to information. Another interesting fact is that corruption perception decreases with socioeconomic status. People who are better-off materially are more likely to view world in favorable light. Self-employed people and people who are working in a private enterprise tend to perceive higher level of corruption than those who are employed in a public sector. This stands for a fact that private businesses are more likely to experience the corrupt behavior, for example when competing for the public tender (Melgar et al., 2010).

Mocan (2008) uses micro level data from 49 countries to create a direct measure of corruption. This research shows that both personal and country characteristics determine the risk of exposure to bribery. Among other variables, author analyses gender, education, the city size or the strength of the institutions in the country. The author links corruption with cultural attributes, economic development, quality of institutions - secure property rights, country characteristics and personal status.

Unlike as the Melgar et al. (2010) this research claims that living in the larger cities increases exposure to bribery. This can be explained by the fact that in cities there are more possibilities to interact with government officials in less personal way than in smaller cities or towns. Furthermore, highly educated and high-income individuals have higher exposure to being asked for a bribe by government official because of their higher earning capacity and because they are likely to have more opportunities to interact with government officials. The opposite holds as well. Young and old people as well as home keepers have fewer interactions with government official and thus, smaller chance to be asked for a bribe. Regarding the gender, men are supposed to be more frequent target of bribery. In many developing countries are males more active in the market than females and therefore they are more exposed to a chance to meet corrupting act. Similarly, Mocan (2008) finds relation between the bribery risk and the level of corruption.

The following researches are focusing the question of personal characteristic through the eyes of cultural values: Husted (1999) examines the impact national wealth, income distribution, government size and cultural variables on the perceived level of corruption. In the analysis he works with the Hofstede four dimensions He found high correlation between the perceived level of corruption and GNP per capita, power distance, masculinity and uncertainty avoidance. He focuses on a model of corruption that shall explain underlying causes or antecedents. The research is focused on a claim that cultural values have significant impact on a wide array of business practices in different countries (Hofstede 1991, Husted 1999). He understands to cultural values as the conceptions of the desirable that are characteristic of particular people.

Husted (1999) analyses the sample of 44 countries. Regarding the corruption perception he uses the data from Transparency International and the cultural values he bases on the Hofstede's research. He found the most significant correlation between the perceived level of corruption and economic level of development measured by the purchasing power parity estimate of GNP per capita. Among other results, this research also shows significant correlation between the cultural variables - power distance, masculinity and uncertainty avoidance - and perceived level of corruption. Husted did not verify individualism as a significant variable due to the fact that individualism is highly correlated with the GNP per capita ${ }^{1}$. The information about the individualism is contained in the variable representing economic development and thus it is not verified as statistically significant.

Connelly and Ones (2008) analyzed the effects of national personality and Hofstede's cultural dimensions on the perceived level of corruption. The national personality was represented by the five-factor model of personality consisting of - neuroticism, extraversion, and openness to experience, agreeableness and conscientiousness. Neuroticism describes the individuals' tendency to be depressed and anxious. Extraversion represents sociability, dominance and

\footnotetext{
1 This was also noted by Hofstede (1997).
} 
activity. Openness to experience is described as the inclination to be interested to learning new ideas and exploring. Agreeableness is individuals' tendency to be kind and polite. And the conscientiousness is composed of cautiousness and dependability. According to the authors the differences in the national personality reflect differences in national character and culture.

This study analyses the sample of 54 countries and uses Corruption Perception Index as the measure of corruption and Revised NEO personality inventory for the measures of the five personality factors. The research showed that nations scoring low in openness and high in neuroticism tended to be more corrupt. Openness to the experience is connected to endorsing politically liberal and nontraditional values. Nations whose citizens would support these ideas would find their citizens more supporting of the corruption repressing legislative. They found negative connection between the extraversion and perceived level of corruption. It is explained with the fact that nations scoring high in extraversion are less submissive and thus they are more likely to report observed acts of corruption. More extraverted nations have more whistle-blowers, closer interpersonal interactions and more critical mass media. Agreeableness on the other hand has showed no relation to the perceived level of corruption (Connelly and Ones, 2008).

The previous researches regarding the basic values have focused on many different areas. The research regarding the core political values and voting (Schwartz et al, 2010) or gender differences and basic human values (Lyons et al, 2005) may be listed as examples. Also, the research exploring the connection between the values and corruption has focused mainly on the cultural values and dimensions based on the Hofstede's cultural dimensions (Husted, 1999 or Connelly and Ones, 2008). This paper continues in this line of research and study the relation between the perceived level of importance of various values and the perceived levels of corruption in 50 countries on macro level.

\section{Hypothesis}

\subsection{Corruption perceptions are related to the subjective importance of values in countries.}

Where the values are the following:

Table 1. The list of values used in the analysis

\begin{tabular}{|l|l|}
\hline$V_{1}$ & importance of creativity, \\
\hline$V_{2}$ & importance of being rich, \\
\hline$V_{3}$ & importance of living in secure surroundings, \\
\hline$V_{4}$ & importance of taking care about ourselves \\
\hline$V_{5}$ & importance of helping others \\
\hline$V_{6}$ & importance of being successful, \\
\hline$V_{7}$ & importance of excitement and adventure, \\
\hline$V_{8}$ & importance to behave according the rules, \\
\hline$V_{9}$ & Importance of taking care about environment \\
\hline$V_{10}$ & importance of tradition \\
\hline
\end{tabular}

\section{Data and Indicators}

\subsection{Corruption Perception Indices}

The standardised data about the perception of corruption are used from the Corruption Perception Index (CPI) which is measured annually by the Transparency International among different countries in the world. Transparency International creates the CPI based on the data from independent institutions focusing on the analysis of the business and government environment. The data for 2006 are available for 163 countries. The lower is CPI the more corrupt is the country.

It is important to note that the corruption perception index does not measure the actual amount of corruption, but only the perceived. The value of the perceived corruption may differ. This index is often criticised, because people may consider corruption in their country to be higher and more important problem in the society that it really is. On the other hand, it may be also underestimated. The question also is how the level of corruption shall be measured. The corrupt behaviour is illegal and very secretive and it is assumed that the number of reported cases of corruption is lower than their actual number.

The inconsistency among the results may be also caused by the fact that the corruption perception index is 
measured within the people working in the business and private sector. The experiences and the personal characteristics of those people may differ and might not reflect the experiences of other people in the society.

Bias may be caused also by the form of the questions asked in the questionnaire or during the interview. In the analysed questions the respondent often decides whether he is similar to the person described in the statement. The collected answers reflect only the fact how the respondent views himself and not what he is really like.

On the other hand Corruption Perception Index is one of the most frequently used indices in empirical research due to its availability and consistency. Though it may not necessary be a perfect measure of corruption, high levels of corruption perception may have more devastating effects than corruption itself (Melgar et al., 2010). Corruption perceptions generate a culture of distrust and may create a cultural tradition of gift giving resulting in the raising of corruption, thus rising institutional instability and the deterioration of the relationships among individuals, institutions and states (Melgar et al., 2010).

\subsection{The subjective importance of values}

For the subjective importance of values we use data collected in the World Value Survey (WVS) in the Wave 5 (2005 to 2009). In this survey the respondents were asked to answer the following questions:

Now I will briefly describe some people. Using this card, would you please indicate for each description whether that person is very much like you, like you, somewhat like you, A little like you, not like you, or not at all like you?

$V_{1}$ - It is important to this person to think up new ideas and be creative; to do things one's own way.

$V_{2}$ - It is important to this person to be rich; to have a lot of money and expensive things.

$V_{3}$ - Living in secure surroundings is important to this person; to avoid anything that might be dangerous.

$V_{4}$ - It is important to this person to have a good time to "spoil" oneself.

$V_{5}$ - It is important to this person to help the people nearby; to care for their well-being.

$V_{6}$ - Being very successful is important to this person to have people recognize one's achievements.

$V_{7}$ - Adventure and taking risks are important to this person; to have an exciting life.

$V_{8}$ - It is important to this person to always behave properly; to avoid doing anything people would say is wrong.

$V_{9}$ - Looking after the environment is important to this person; to care for nature.

$V_{10}$ - Tradition is important to this person; to follow the customs handed down by one's religion or family.

The answers are coded on the scale from 1 - Very much like you to the 6 - Not at all like you.

For each country we compute the percentages of respondents who had answered very much like them, like them and somewhat like them. The number of countries for which are the data available is 52 .

\subsection{Control variables}

As control variables we employ GDP per capita, change of GDP per capita, the level of education measured as a percentage of country's citizens with completed secondary education and urbanisation as the percentage of population of a country living in the cities. The data were collected by the World Bank in the year 2006.

\section{Methodology}

To identify the connection between the corruption perception and personal characteristics I will use similar framework as developed by Conelly and Ones (2008) connected with the contributions of Mocan (2008). This framework is based on the assumption that the level of the development of the country is connected with its legal, political and economic characteristics. The analysis starts with an estimation of cross-country regression of the following linear equation (1)

$C P I=a_{0}+a_{1} V_{i}+a_{2} Z+e$

Where

CPI denotes the Corruption Perception Index for each country for the year 2006.

Vi represents a particular value (see table 1). To avoid multicollienarity compute the regression for each values separately.

$Z$ represents the common regression control variables that have been identified by previous studies as possible transmission channels for corruption: wealth, growth, education and urbanisation.

e represents the error term. 
To estimate the overall effect of corruption it is important to define the equation for the variables which may have also effect on the corruption perception:

$$
\mathrm{Z}=\mathrm{f}(\mathrm{CPI}, \mathrm{Econ})
$$

where the Econ refers to economic factors. Mocan (2008) notes, that economic factors are negatively impacted to the extent of the corruption in the country. This reflects following equation:

Econ $=f(C P I, G D P, V i, E)$

where the CPI represents the level of corruption which has an impact on the economic development. Scott (1972) notes that the existence of more equal distribution of wealth refers to the existence of the middle class, which refers to a certain level of purchasing power and thus, promotes the economic development. E represents the human capital measures that impact economic development, such as the level of the education in the country.

When we substitute the equation (3) into (2), the result is macro reduced form:

$Z=f\left[C P I, V_{i}, \ln (G D P), E\right]$

GDP enters the regression in logarithmic form to prevent multicollinearity. $E$ denotes to the percentage of respondents who gained a university degree. Conelly and Ones (2008) include into the equation the annual change of the GDP and the urbanisation in the country $\triangle$ GDP represents the annual change in the GDP per capita

$\left.\Delta \mathrm{GDP}=\mathrm{GDP}_{\mathrm{t}-\mathrm{GDP}} \mathrm{t}-1\right) / \mathrm{GDP} \mathrm{t}_{\mathrm{t}}$

$U$ stands for the percentage of respondents living in the cities.

Thus, the final form of the equation shall be:

$\mathrm{Z}=\mathrm{f}[\mathrm{CPI}, \ln (\mathrm{GDP}), \Delta \mathrm{GDP}, \mathrm{E}, \mathrm{U}]$

Substituting of the equation $Z(6)$ into the equation (1) generates the resulting equation:

$C P I=a_{0}+a_{1} V_{i}+a_{2} \ln (G D P)+a_{3} \Delta G D P+a_{4} E+a_{5} U+e$

Analysed countries: Andorra, Argentina, Australia, Brazil, Bulgaria, Canada, Chile, China, Taiwan, Cyprus, Ethiopia, Finland, France, Georgia, Germany, Ghana, Hungary, India, Indonesia, Iran, Japan, Jordan, South Korea, Malaysia, Mali, Mexico, Moldova, Morocco, Netherlands, Norway, Peru, Poland, Romania, Russia, Rwanda, Viet Nam, Slovenia, South Africa, Spain, Sweden, Switzerland, Thailand, Trinidad and Tobago, Turkey, Ukraine, Egypt, Great Britain, United States, Burkina Faso, Uruguay, Serbia and Montenegro, Zambia.

\section{Results}

The results of OLS regressions according to the formula 7 is presented in tables 2 and 3

Table 2. Results of OLS regression analysis. Dependent variable - Corruption Perception index

\begin{tabular}{|c|c|c|c|c|c|c|c|c|c|c|}
\hline & \multicolumn{2}{|c|}{$V_{1}$ (creativity) } & \multicolumn{2}{|c|}{$V_{2 \text { (being rich) }}$} & \multicolumn{2}{|c|}{$V_{3}$ (secure surroundings) } & \multicolumn{2}{|c|}{$V_{4}$ (care about ourselves) } & \multicolumn{2}{|c|}{$V_{5}$ (helping others) } \\
\hline & Coef. & P-value & Coef. & P-value & Coef. & P-value & Coef. & P-value & Coef. & P-value \\
\hline Constant & $-4,139^{\star \star}$ & 0,049 & $-3,780^{*}$ & 0,088 & $-1,459$ & 0,510 & $-2,822$ & 0,126 & $-2,378$ & 0,260 \\
\hline $\mathrm{V}_{\mathrm{i}}$ & 0,023 & 0,146 & 0,014 & 0,296 & $-0,009$ & 0,558 & 0,008 & 0,473 & 0,001 & 0,951 \\
\hline In GDP per capita (USD) & $1,093^{* * *}$ & 0,000 & $1,244^{* * *}$ & 0,000 & $1,119^{\star * *}$ & 0,000 & $1,138^{\star * *}$ & 0,000 & $1,134^{\star \star *}$ & 0,000 \\
\hline GDP growth & $-0,236^{* *}$ & 0,013 & $-0,252^{* * *}$ & 0,009 & $-0,250^{* *}$ & 0,010 & $-0,239^{* *}$ & 0,015 & $-0,253^{* *}$ & 0,011 \\
\hline Education & $-0,009$ & 0,470 & $-0,016$ & 0,198 & $-0,016$ & 0,200 & $-0,014$ & 0,284 & $-0,015$ & 0,233 \\
\hline Urbanisation & $-0,006$ & 0,620 & $-0,007$ & 0,570 & $-0,009$ & 0,492 & $-0,010$ & 0,455 & $-0,009$ & 0,505 \\
\hline R2 & \multicolumn{2}{|c|}{0,763} & \multicolumn{2}{|c|}{0,758} & \multicolumn{2}{|c|}{0,753} & \multicolumn{2}{|c|}{0,745} & \multicolumn{2}{|c|}{0,751} \\
\hline $\mathrm{N}$ & \multicolumn{2}{|c|}{50} & \multicolumn{2}{|c|}{50} & \multicolumn{2}{|c|}{50} & \multicolumn{2}{|c|}{50} & \multicolumn{2}{|c|}{50} \\
\hline
\end{tabular}

Source: Own analysis

Table 3. Results of OLS regression analysis. Dependent variable - Corruption Perception index

\begin{tabular}{|c|c|c|c|c|c|c|c|c|c|c|}
\hline & \multicolumn{2}{|c|}{$V_{6}$ (being successful) } & \multicolumn{2}{|c|}{$V_{7}$ (excitement and adventure) } & \multicolumn{2}{|c|}{$V_{8}$ (rules) } & \multicolumn{2}{|c|}{$V_{9}$ (environment) } & \multicolumn{2}{|c|}{$V_{10}$ (tradition) } \\
\hline & Coef. & P-value & Coef. & P-value & Coef. & P-value & Coef. & P-value & Coef. & P-value \\
\hline Constant & $-1,198$ & 0,573 & $-3,091$ & 0,129 & 0,800 & 0,716 & $-2,192$ & 0,316 & 0,958 & 0,666 \\
\hline $\mathrm{V}_{\mathrm{i}}$ & $-0,013$ & 0,401 & 0,011 & 0,480 & $-0,032^{* *}$ & 0,044 & $-0,001$ & 0,937 & $-0,030^{* *}$ & 0,039 \\
\hline In GDP per capita (USD) & $1,108^{* \star *}$ & 0,000 & $1,156^{* * *}$ & 0,000 & $1,033^{* * *}$ & 0,000 & $1,136^{* * *}$ & 0,000 & $0,987^{* * *}$ & 0,000 \\
\hline GDP growth & $-0,241^{* *}$ & 0,014 & $-0,248^{\star *}$ & 0,011 & $-0,223^{* *}$ & 0,018 & $-0,251^{* *}$ & 0,011 & $-0,235^{* *}$ & 0,012 \\
\hline Education & $-0,017$ & 0,189 & $-0,014$ & 0,277 & $-0,018$ & 0,147 & $-0,016$ & 0,224 & $-0,015$ & 0,201 \\
\hline Urbanisation & $-0,011$ & 0,416 & $-0,007$ & 0,567 & $-0,008$ & 0,539 & $-0,009$ & 0,509 & $-0,007$ & 0,585 \\
\hline
\end{tabular}




\begin{tabular}{|l|c|c|c|c|}
\hline $\mathrm{R} 2$ & 0,755 & 0,754 & 0,774 & 0,752 \\
\hline $\mathrm{N}$ & 50 & 50 & 50 & 50 \\
\hline
\end{tabular}

\section{Source: Own analysis}

The results presented in table 2 and 3 suggest, that out of ten value indicators two proved to be statistically significant on conventional levels - corruption perceptions are related to rules and traditions.

- The more respondents of the studied countries believe, that it is important to always behave properly; to avoid doing anything people would say is wrong, the higher is perceived corruption in the countries.

These values intrinsically correspond to implicit institutions that enforce rules and norms of behaviour and the level of social conformity present in the countries. Naturally in the case that corruption is embedded in the country, conformity to the implicit rules may mean higher corruption. On the other hand, if uncovered, corruption may mean greater personal problem as the person may be officially and implicitly persecuted (Root, 1996; Hofstede 1991).

- The more respondents of the studied countries believe, that it is important to comply with tradition and to follow the customs handed down by one's religion or family, the higher is the perceived corruption in the countries.

The factor of tradition exacerbates and explains path dependency of corruptive climate and the prevalence of corruption. In particular, countries with Protestant traditions were found to be less corrupt (Treisman, 2000; Gokcekus, 2008, North, et al. 2013) since "the religious traditions of Protestant institutions of the church...may play a role in monitoring and denouncing abuses by state officials," ( Treisman, 2000, p.403).Traditionally tight family relationships, especially in the case of extended families, lead to higher corruption especially in developing countries for "corruption or even theft can be acceptable as long as it is perceived to bring benefits to the family, kinship or community" (Bukuluki, 2013, p.27). Naturally, family tradition and connections in business or government tend to increase corruption (Seleim, Bontis, 2009). The whole dimension of collectivism implying tight and emotionally important family relationships is proven to be substantially correlated with corruption (Zheng, et al, 2013; Mazar and Aggarwal, 2011; Pillay, and Dorasamy, 2010). In all these aspects our results correspond to the results cited above.

The other variables significant in our analysis were GDP per capita (USD) and GDP growth in a way, that

- The higher is In GDP per capita, the lower is perceived corruption

- The higher is GDP growth, the higher is perceived corruption.

The first finding supports the previous numerous findings on the relation between GDP and corruption perceptions (see Japos, and Estrada, 2014; Okada and Samreth, 2012; Elbahnasawy, 2014; Iwasaki and Suzuki, 2012). This relation was well studied in the literature and most of the authors support the positive sign. The second finding contradicts the findings existing in the literature (see Braun and Di Tella, 2004; Frechette, 2006, Berdiev, et al 2013). Berdiev, et al (2013) finds, that GDP per capita growth significantly increases corruption. He explains his finding in the way that if people are poor enough little can be taken from them by corrupt behavior. As income rises, there is more to gain through corruption (Berdiev, et al, 2013). One can notice that this kind of explanation explains rather relation of CPI with GDP than CPI and GDP growth. It is also important to mention that Berdiev et al. (2013) did not control for GDP per capita in his analysis.

None of the other control variables - education and urbanization - showed statistically significant relation to the analyzed characteristics.

\section{Conclusion}

This paper analysed the relation of the subjective importance of values such as creativity, being rich, taking care of ourselves, helping others, being successful, excitement and adventure, behaving according to rules, taking care of the environment, tradition, living in secure surrounding in countries and the perceived levels of corruption in countries. We run OLS regression analysis employing data on corruption perceptions collected by Transparency International (corruption perception index), data on values collected by World Values Survey. Our results suggest, that the more it is important for population to always behave properly; to avoid doing anything people would say is wrong, the higher is perceived corruption in the countries. The more it is important to comply with tradition and to follow the customs handed down by one's religion or family, the higher is the perceived corruption in the countries.

In addition we study the effects of GDP per capita, and GDP per capita growth on corruption perceptions. We 
control for the level of education and urbanization. While the relationship of CPI and GDP is well researched in the literature (see Japos, and Estrada, 2014; Okada and Samreth, 2012; Elbahnasawy, 2014; Iwasaki and Suzuki, 2012) and the results are consistent (all the researchers report positive statistically significant association), the results on CPI and GDP growth exhibit certain controversy. Although some authors report positive relation between GDP growth and corruption (see Braun and Di Tella, 2004; Frechette, 2006; or Berdiev et al. 2013), the results of this study support negative statistically significant association between CPI and GDP growth. The difference between the two suggested results may be explained by the fact that the previous results did not take into account GDP per capita.

\section{References}

Andvig, C. (1991) The economics of corruption: a survey. Studwe Economici, 43, 57-94.

Berdiev, A. N., Kim, Y., and Chang, C. P. (2013). Remittances and corruption. Economics Letters, 118(1), 182-185.

Bukuluki, P. (2013). "When I steal, it is for the benefit of me and you": Is collectivism engendering corruption in Uganda?. International Letters of Social and Humanistic Sciences, (05), 27-44.

Cabelkova, I., and Strielkowski, W. (2013). Is the level of taxation a product of culture? A cultural economics approach. Society and Economy, 35(4), 513-529

Connelly, B. S., and Ones, D. S. (2008). The personality of corruption a national-level analysis. Cross-cultural research, 42(4), 353-385.

DeBacker, J., Heim, B. T., and Tran, A. (2012). Importing corruption culture from overseas: Evidence from corporate tax evasion in the United States. Journal of Financial Economics, Vol. 117, Iss. 1, 122-128

Elbahnasawy, N. G. (2014). E-government, internet adoption, and corruption: An empirical investigation. World Development, 57, 114126.

Frechette, G.R. (2006) Panel data analysis of the time-varying determinants of corruption, CIRANO Working Paper.

Gokcekus, O. (2008). Is it protestant tradition or current protestant population that affects corruption?. Economics Letters, 99(1), 59-62.

Harrison, L. E., and Huntington, S. P. (Eds.). (2000). Culture matters: How values shape human progress. Basic Books.

Hofstede, G. (1991) Cultures and Organizations, McGraw-Hill International Ltd, London.

Husted, B. W., and Instituto Tecnologico y de Estudios. (1999). Wealth, culture, and corruption. Journal of International Business Studies, 339-359.

Imasaki, I., and Suzuki, T. (2012). The determinants of corruption in transition economies. Economics Letters, 114(1), 54-60.

Japos, G. V., and Estrada, R. D. (2014). GDP Per Capita, Economic Freedom Index, Political Culture and Freedom of the Press Index as Determinants of Corruption Perception Index: A Global Study. International Journal on Graft and Corruption Research, 1(1).

Koudelková, P., Strielkowski, W., and Hejlova, D. (2015). Corruption and System Change in the Czech Republic: Firm-level Evidence. DANUBE: Law and Economics Review, 6(1), 25-46

Lipset, S. M., and Lenz, G. S. (2000). Corruption, culture, and markets. Culture matters: How values shape human progress, 112.

Lyons, S., Duxbury, L., and Higgins, C. (2005). Are gender differences in basic human values a generational phenomenon? Sex roles. 53(9-10), 763-778.

M. Braun, and R. Di Tella (2004). Inflation, inflation variability, and corruption. Economics and Politics, 16, 77-100

Mauro, P. (1996). The effects of corruption on growth, investment, and government expenditure, IMF Working Paper, WP/96/98.

Mazar, N., and Aggarwal, P. (2011). Greasing the palm can collectivism promote bribery? Psychological Science, 22(7), 843-848.

Melgar, N., Rossi, M., and Smith, T. W. (2010). The perception of corruption. International Journal of Public Opinion Research, 22(1), 120-131.

Mocan, N. (2008). What determines corruption? International evidence from microdata. Economic Inquiry, 46(4), 493-510.

North, C. M., Orman, W. H., and Gwin, C. R. (2013). Religion, corruption, and the rule of law. Journal of Money, Credit and Banking, 45(5), 757-779.

Okada, K., and Samreth, S. (2012). The effect of foreign aid on corruption: A quantile regression approach. Economics Letters, 115(2), 240-243.

Pillay, S., and Dorasamy, N. (2010). Linking cultural dimensions with the nature of corruption: An institutional theory perspective. International Journal of Cross Cultural Management, 10(3), 363-378.

Root, H. (1996). Corruption in China: has it become systemic?. Asian Survey, 741-757.

Rose-Ackerman, S. (1997) Corruption and development, Annual Bank Conference on Development Economics, 30 April and 1 May, Washington D.C.

Sanderson, M., and Strielkowski, W. (2013). Structural Channels for Ukrainian Labor Migration in the Czech Republic. Trames, (3), 313323

Sandholtz, W., and Taagepera, R. (2005). Corruption, culture, and communism. International Review of Sociology, 15(1), 109-131.

Schwartz, S. H., Caprara, G. V., and Vecchione, M. (2010). Basic personal values, core political values, and voting: A longitudinal analysis. Political Psychology, 31(3), 421-452.

Scott, J. C. (1972). Comparative political corruption. Prentice Hall.

Seleim, A., and Bontis, N. (2009). The relationship between culture and corruption: a cross-national study. Journal of Intellectual Capital, 10(1), 165-184.

Sims, R. L., Gong, B., and Ruppel, C. P. (2012). A contingency theory of corruption: The effect of human development and national 
culture. The Social Science Journal, 49(1), 90-97.

Strielkowski, W., and Čábelková, I. (2014). Interdependence between taxation, cultural values and the role of the state in economic life. International Economics Letters, 2(4), 19-29

Tanzi, V. (1998) Corruption around the world: causes, consequences, scope, and cures, IMF Working Paper, WP/98/63.

Treisman, D. (2000). The causes of corruption: a cross-national study. Journal of public economics, 76(3), 399-457.

Zheng, X., El Ghoul, S., Guedhami, O., and Kwok, C. C. (2013). Collectivism and corruption in bank lending. Journal of International Business Studies, 44(4), 363-390. 